\title{
Metabolic Engineering of Escherichia Coli for Ectoine Production With the Fermentation Strategy of Supplementing Amino Donor
}

\author{
Hao Zhang \\ Nanjing Tech University \\ Yingying Cao \\ Nanjing Tech University \\ Yingsheng Dong \\ Nanjing Tech University \\ Ming Zhao \\ Nanjing Tech University \\ Yanqin Ma \\ Nanjing Tech University \\ Zhengshan Luo \\ Nanjing Tech University
}

Sha Li ( $\square$ lisha@njtech.edu.cn )

Nanjing Tech University https://orcid.org/0000-0001-8256-1263

Hong Xu

Nanjing Tech University

\section{Research}

Keywords: Ectoine, Escherichia coli, Metabolic engineering, Medium optimization, Amino donor, RT qPCR

Posted Date: December 28th, 2020

DOI: https://doi.org/10.21203/rs.3.rs-134030/v1

License: (c) (i) This work is licensed under a Creative Commons Attribution 4.0 International License. Read Full License

Version of Record: A version of this preprint was published at Frontiers in Bioengineering and Biotechnology on January 25th, 2022. See the published version at https://doi.org/10.3389/fbioe.2022.824859. 


\section{Abstract}

Background: Ectoine, a compatible solute, has broad application prospects in food biotechnology, agriculture, medicine, and cosmetics because of its protective action on biological compounds. Industrially, ectoine is produced by halophilic bacteria in a complex process. Recently, various works focus on improving ectoine production by using engineered strains, but there are still problems of low yield and low ectoine production efficiency.

Results: To overcome the drawback, a final metabolic engineered strain E. coli ET08 was constructed by eliminating lysine synthesis branch and by-product metabolic pathways, and ectoine production reached $10.2 \mathrm{~g} / \mathrm{L}$ through culture medium optimization. Compared with nitrate, addition of ammonium salt contributed more to the ectoine synthesis. Furthermore, the ammonium sulphate boosted more ectoine titers than ammonium chloride and sodium glutamate. The analysis of transcriptional levels revealed that the ammonium sulfate enhanced ectoine biosynthesis by enhancing metabolic flux toward ectoine biosynthesis and providing affluent synthetic precursors. Ultimately, the ectoine production and yield of the E. coli ET08 reached $36.5 \mathrm{~g} / \mathrm{L}$ and $0.3 \mathrm{~g} / \mathrm{g}$ glucose with supplementing amino donor in a $7.5 \mathrm{~L}$ bioreactor.

Conclusions: a novel potential metabolic engineered Escherichia coli for ectoine production was constructed. optimizing amino donor and analyzing the transcription levels conclude that ammonium sulfate, as the optimal amino donor, has a positive effect on ectoine synthesis. It is the first report about the effect of exogenous amino donor on ectoine fermentation by metabolic engineered strain. The maximum ectoine production and yield from glucose synthesized by $E$. coli were obtained by two-stage feeding fermentation with supplementing amino donor. It provides a novel strategy for the synthesis of ectoine by engineered strain in industry. This research provides the basis for an effective process for ectoine production, together with the further applications of ectoine in food and cosmetics, and could also be used to produce other high value amino acid derivative.

\section{Background}

As a compatible solute, ectoine (1,4,5,6-tetrahydro-2-methyl-4-pyrimidinecarboxylicacid) was commonly found in halophilic and halotolerant microorganisms. It was first discovered in Ectothiorhodospira halochloris by Galinski et al. [1] and its structure was identified to be a cyclic amino acid derivative. In addition to its primary function of maintaining cell osmotic balance and resisting the impact of high osmotic pressure, an increasing attention was focused on its remarkable ability in protecting biological compounds $[2,3]$. Therefore the potential applications of ectoine lies in food biotechnology, agriculture, skin caring, and medical fields [4-8].

As shown in Figure. 1, ectoine is synthesized from the precursor L-aspartate- $\beta$-semialdehyde (ASA), a central hub in microbial amino acid production, by three successive enzymatic steps that are catalyzed by the L-2,4diaminobutyrate transaminase (EctB), the 2,4-diaminobutyrate acetyltransferase (EctA) and the ectoine synthase (EctC) [9-12]. The ectoine biosynthetic genes are normally organized in an operon (ectABC) that might also comprise the ectD gene [13]. Similar gene clusters involved in ectoine biosynthesis were disclosed in strain Marinococcus halophilus [14], Halobacillus dabanensis D-8T [15], Methylomicrobium alcaliphilum 20Z [16], Nesterenkonia halobia DSM20541 [17] and so on.

Commercially, ectoine production is realized through fermentation of halophiles in a special and complex process called "bacterial milking" $[18,19]$. Although this method can be used to obtain ectoine in large scale, the use of large amounts of salt will corrode the equipment, which requires higher corrosion resistance of the fermentation equipment. The ability of bacteria to resist osmotic pressure shock needs to be higher in the process. To address the 
shortcomings of this process, great efforts have been made, such as optimizing process conditions, improving ectoine production performance by breeding of halophilic bacteria. However, using transgenic nonhalophilic bacteria for ectoine production is more efficient in recent years.

Therefore, Becker et al. successfully integrated the ectABCD gene operon of Pseudomonas stutzeri A1501 into Corynebacterium glutamicum based on systematic metabolic engineering, and mutated aspartate kinase to ensure sufficient supply of ASA, and the final overall spacetime yield achieved $6.7 \mathrm{~g} / \mathrm{L}$ ectoine per day [20]. In 2015, ectABC gene cluster of Halomonas elongata DSM 2581 was over expressed in E. coli K-12/BW25113, and the titer of ectoine reached $25.1 \mathrm{~g} / \mathrm{L}$, with a productive yield of $4048 \mathrm{mg} / \mathrm{g}$ DCW by a whole cell biocatalytic process using aspartate and glycerol as substrates [21]. Subsequently, an engineered strain E. coliECT05 was constructed through a series of metabolic engineering strategies, besides the final titer reached $25.1 \mathrm{~g} / \mathrm{L}$, and overall ectoine yield was $0.11 \mathrm{~g} / \mathrm{g}$ of glucose [22]. Recently, production of ectoine was up to $65 \mathrm{~g} / \mathrm{L}$ within $56 \mathrm{~h}$ by transcriptional balancing of the ectoine pathway in Corynebacterium. glutamicum [23].

Although the ectoine production can be realized by fermentation of engineered strains, there are still problems of low glucose conversion rate and low ectoine production efficiency. The recent reports mainly focus on metabolic modification of engineered strains. There were few studies on nutritional requirements optimization and fermentation regulation of engineered strains. Particularly, nitrogen is a constituent of cellular components such as proteins, nucleic acids and several cofactors. It also regulates primary and secondary metabolism in different bacteria. Xu et al. increased the yield of $\varepsilon$-poly-L-lysine through nitrogen source regulation and optimization [24]. It was also reported that nitrogen source regulation has great effect on ethanol and antibiotic production $[25,26]$. Ectoine is synthesized from aspartate, which acts as the direct precursor. The supply of amounts of nitrogen is essential for ectoine synthesis.

In this study, we constructed a metabolically engineered strain E. coli ET08 capable of producing ectoine efficiently. Further studies focus on the effects of complex nitrogen sources and amino donors on ectoine production. Then the transcription levels of the key genes in ectoine and ammonium metabolic pathways were analyzed for description the function of the amino donor. Finally, ectoine production of engineered E. coli ET08 was evaluated by two-stage feeding fermentation with supplementing amino donor. This work provides a novel strategy for the synthesis of ectoine by engineered strain in industry.

\section{Results And Discussion}

\section{Construction of engineered $E$. coli for ectoine production}

For heterologous synthesis of ectoine in E. coli, the basic strains E. coli MG1655 and E. coli BL21 (DE3) were chosen as hosts in light of their clear genetic background. The constructed plasmids pTrc-ectABC and pET- ectABC were transferred into E. coli MG1655 and E. coli BL21 (DE3), to form the strain ET01 and ET02 respectively (Table 1). The extracellular ectoine titer reached $0.52 \mathrm{~g} / \mathrm{L}$ after $48 \mathrm{~h}$ cultivation with ET01 (Table 2). Although the protein expression levels of ectABC in ET02 were more powerful than those of ectABC in ET01 (see Additional file 1: Figure. S1), and the biomass of ET02 was higher than that of ET01, the ectoine titer of the strain ET02 could not be detected (Table 2). The results clearly indicated that ET01 performed best and thus was chosen for further genetic manipulation. 
Table 1

Strains and plasmids used in this study.

\begin{tabular}{|c|c|c|}
\hline Strains/plasmid & Relevant characteristic & Source \\
\hline \multicolumn{3}{|l|}{ Strains } \\
\hline E. coli MG1655 & Wild type & This lab \\
\hline E. coli BL21 (DE3) & Expression host & This lab \\
\hline Halomonas venusta & Wild type & This lab \\
\hline ET01 & MG1655 (pTrc-ectABC) & This study \\
\hline ET02 & BL21 (pET-ectABC) & This study \\
\hline ET03 & ET01 $\Delta / y s A$ & This study \\
\hline ET04 & ET01 $\Delta$ thrA & This study \\
\hline ET05 & ET03 $\Delta$ thrA & This study \\
\hline ET06 & ET03 $\Delta p t a$ & This study \\
\hline ET07 & ET03 $\Delta / d h A$ & This study \\
\hline ET08 & ET03 $\Delta p y k F$ & This study \\
\hline \multicolumn{3}{|l|}{ Plasmid } \\
\hline pTrc99a & trc promoter, cloning vector, $\mathrm{Amp}^{\mathrm{r}}$ & This lab \\
\hline pET-28a & T7promoter, cloning vector, $\mathrm{Kan}^{\mathrm{r}}$ & This lab \\
\hline pKD46 & Temperature sensitive vector carrying Red recombinase, Amp ${ }^{r}$ & This lab \\
\hline pKD3 & Template vector, $\mathrm{Cm}^{\mathrm{r}}$ & This lab \\
\hline pCP20 & Temperature sensitive vector carrying FLP recombinase, Amp ${ }^{r}$ & This lab \\
\hline pTrc-ect $A B C$ & pTrc99a containing Halomonas venuas ectABC gene & This study \\
\hline pET-ectABC & pET28a containing Halomonas venuas ectABC gene & This study \\
\hline
\end{tabular}


Table 2

Comparison of fermentation parameters of different strains in shake flask cultivations.

\begin{tabular}{|lllll|}
\hline Strain & $\begin{array}{l}\text { Ectoine titer } \\
(\mathbf{g} / \mathbf{L})\end{array}$ & $\begin{array}{l}\text { Glucose consumption } \\
(\mathbf{g} / \mathbf{L})\end{array}$ & $\begin{array}{l}\text { DCW } \\
(\mathbf{g} / \mathbf{L})\end{array}$ & $\begin{array}{l}\text { Ectoine yield on glucose } \\
\mathbf{( g / g})\end{array}$ \\
\hline ET01 & $0.52 \pm 0.01$ & $65 \pm 1.37$ & $16.2 \pm 0.39$ & 0.01 \\
\hline ET02 & 0 & $65 \pm 1.72$ & $18 \pm 0.41$ & 0 \\
\hline ET06 & $1.09 \pm 0.21$ & $65 \pm 1.43$ & $14.3 \pm 0.29$ & 0.02 \\
\hline ET07 & $0.6 \pm 0.07$ & $45 \pm 0.91$ & $14.3 \pm 0.32$ & 0.01 \\
\hline ET08 & $1.87 \pm 0.18$ & $63 \pm 1.8$ & $15.02 \pm 0.48$ & 0.03 \\
\hline
\end{tabular}

\section{Elimination of branch and by-product metabolic pathways}

L-aspartate- $\beta$-semialdehyde is the important precursor of L-threonine, L-lysine and ectoine synthesis pathway in $E$. coli [12]. To reduce L-aspartate- $\beta$-semialdehyde shunting by the branch metabolism, the genes of lys $A$ (encoding diaminopimelate decarboxylase) and thrA (encoding aspartate kinase/homoserine dehydrogenase) in E. coli ET01 were knocked out individually and together, generating the strains E. coli ET03, E. coli ET04 and E. coli ET05 respectively. As shown in Figure. 2, in comparison to that of E. coli ET01, the ectoine titer of E. coli ET03 (1.08 g/L) increased by 1.08 folds but biomass $(13.9 \mathrm{~g} / \mathrm{L})$ decreased at the same glucose consumption $(65 \mathrm{~g} / \mathrm{L})$. When thrA was deleted, ectoine titer of $E$. coli ET04 decreased to $0.34 \mathrm{~g} / \mathrm{L}$ while glucose consumption and cell growth showed the similar trend, declining to $58 \mathrm{~g} / \mathrm{L}$ and $8.2 \mathrm{~g} / \mathrm{L}$ respectively. Similarly, as $/ y s A$ and thrA were knocked out together, ectoine titer of E. coli ET05 decreased to a lower level $(0.2 \mathrm{~g} / \mathrm{L})$ with $53 \mathrm{~g} / \mathrm{L}$ glucose consumption and $7.05 \mathrm{~g} / \mathrm{L} \mathrm{DCW}$. The result indicated that the deletion of thrA greatly inhibited the growth of E. coli ET01 and had negative impact on the ectoine synthesis. This might be due to the fact that thrA is involved in the synthesis of many important amino acids such as homoserine, methionine and threonine which are necessary for the cell growth. The deletion of thrA inhibited the synthesis of amino acids, and consequently the biomass decreased notably. Finally, E. coli ET03 was chosen for further study.

In addition to ectoine, some quantitative organic acids such as acetate, pyruvate and lactate were thought to be in the substrate. The productions of organic acids distribute the carbon flux and could significantly inhibit the cell growth by reducing the $\mathrm{pH}$ level, thereby affecting the titer. To further increase the ectoine production, E. coli ET06, $E$. coli ET07, E. coli ET08 were constructed by deletion of pta, IdhA, and pykF in E. coli ET03 respectively, which are the genes encoding key enzyme in acetate, lactate and pyruvate synthetic pathway respectively (Table 1). When pta was deleted, the ectoine production and biomass of E. coli ET06 were nearly equal to those of E. coli ET03, but the lag phase of E. coli ET06 was extended. However, the ectoine titer of E. coli ET08 increased by $73.1 \%$ (reached to $1.87 \mathrm{~g} / \mathrm{L}$ ) compared with that of E. coli ET03. Meanwhile the titer of E. coli ET07 was $0.6 \mathrm{~g} / \mathrm{L}$ with the lowest glucose consumption $(45 \mathrm{~g} / \mathrm{L})$. These results indicated that the deletion of pta and $/ d h A$ had a negative impact on the production and biomass, while knocking out $p y k F$ could increase the ectoine titer. This might be due to the positive role that the weakening of pyruvate pathway played in the accumulation of phosphoenolpyruvate, a prerequisite for ectoine synthesis. E. coli ET08 was chosen as the potential strain for further study on optimization of fermentation.

\section{Optimization of nitrogen sources for ectoine production}


Nitrogen is a constituent of cellular components such as proteins, nucleic acids and several cofactors [27]. It also regulates primary and secondary metabolism in different bacteria. To further improve the ectoine production, the effects of nitrogen sources combined with yeast extract and inorganic nitrogen sources on ectoine titer were investigated. As shown in Table 3, with the increase of yeast extract concentration in the medium, the ectoine production of E. coli ET08 presented an increasing trend except for the titer obtained by sodium nitrate addition. The noticeable ectoine yield $(7.3 \mathrm{~g} / \mathrm{L})$ was achieved at the combination of $20 \mathrm{~g} / \mathrm{L}$ yeast extract and $152 \mathrm{mM}$ ammonium chloride as inorganic nitrogen source. And the ectoine yield obtained by ammonium chloride addition was 3.9 times higher than that of the control. At the same yeast extract concentration, the ectoine titer gained by ammonium chloride addition was significantly higher than that of the blank control and that obtained by sodium nitrate addition. The combination of yeast extract and nitrate had no positive effect on the production of ectoine. Both the biomass and sugar consumption capacity of E. coli ET08 were also reduced to a certain extent (Table 3). This implied that ammonium salt played a more significant role in promoting the production of ectoine during fermentation compared with nitrate salt. The former was more conducive to microbial absorption in comparison with the latter and acted as exogenous amino donor to provide $\mathrm{NH}_{4}{ }^{+}$involved in the synthesis of glutamate directly (Figure. 1). Besides, glutamate, as a co-substrate, was involved in the catalytic reaction of the key enzyme EctB in the synthesis pathway of ectoine, and it provided an amidogen to L-aspartate- $\beta$-semialdehyde [12].

Table 3

Effect of the yeast extract mixed with inorganic nitrogen on ectoine fermentation.

\begin{tabular}{|c|c|c|c|c|c|c|c|c|c|}
\hline $\begin{array}{l}\text { Yeast extract } \\
(\mathrm{g} / \mathrm{L})\end{array}$ & 10 & & & 15 & & & 20 & & \\
\hline $\begin{array}{l}\text { Inorganic } \\
\text { nitrogen }\end{array}$ & $\mathrm{CK}$ & $\begin{array}{l}152 \mathrm{mM} \\
\mathrm{NH}_{4} \mathrm{Cl}\end{array}$ & $\begin{array}{l}152 \mathrm{mM} \\
\mathrm{NaNO}_{3}\end{array}$ & CK & $\begin{array}{l}152 \mathrm{mM} \\
\mathrm{NH}_{4} \mathrm{Cl}\end{array}$ & $\begin{array}{l}152 \mathrm{mM} \\
\mathrm{NaNO}_{3}\end{array}$ & CK & $\begin{array}{l}152 \mathrm{mM} \\
\mathrm{NH}_{4} \mathrm{Cl}\end{array}$ & $\begin{array}{l}152 \mathrm{mM} \\
\mathrm{NaNO}_{3}\end{array}$ \\
\hline $\begin{array}{l}\text { Ectoine titer } \\
(\mathrm{g} / \mathrm{L})\end{array}$ & $\begin{array}{l}0.37 \\
\pm 0.03\end{array}$ & $\begin{array}{l}1.35 \pm \\
0.07\end{array}$ & $\begin{array}{l}0.47 \pm \\
0.04\end{array}$ & $\begin{array}{l}1.26 \\
\pm 0.11\end{array}$ & $\begin{array}{l}4.19 \pm \\
0.18\end{array}$ & $\begin{array}{l}0.23 \pm \\
0.05\end{array}$ & $\begin{array}{l}1.87 \\
\pm 0.18\end{array}$ & $\begin{array}{l}7.3 \pm \\
0.18\end{array}$ & $\begin{array}{l}0.21 \pm \\
0.02\end{array}$ \\
\hline $\begin{array}{l}\text { Glucose } \\
\text { consumption } \\
(\mathrm{g} / \mathrm{L})\end{array}$ & $\begin{array}{l}59 \pm \\
1.23\end{array}$ & $\begin{array}{l}59 \pm \\
1.30\end{array}$ & $\begin{array}{l}41 \pm \\
0.47\end{array}$ & $\begin{array}{l}64 \pm \\
1.63\end{array}$ & $\begin{array}{l}60.6 \pm \\
0.95\end{array}$ & $\begin{array}{l}46 \pm \\
0.94\end{array}$ & $\begin{array}{l}63 \pm \\
1.8\end{array}$ & $\begin{array}{l}61.5 \pm \\
1.6\end{array}$ & $\begin{array}{l}47 \pm \\
1.27\end{array}$ \\
\hline DCW (g/L) & $\begin{array}{l}10.97 \\
\pm 0.5\end{array}$ & $\begin{array}{l}12.06 \pm \\
0.36\end{array}$ & $\begin{array}{l}9.27 \pm \\
0.39\end{array}$ & $\begin{array}{l}12.79 \\
\pm 0.43\end{array}$ & $\begin{array}{l}13.06 \pm \\
0.34\end{array}$ & $\begin{array}{l}11.03 \pm \\
0.47\end{array}$ & $\begin{array}{l}15.02 \\
\pm 0.48\end{array}$ & $\begin{array}{l}14.8 \pm \\
0.34\end{array}$ & $\begin{array}{l}11.60 \pm \\
0.42\end{array}$ \\
\hline
\end{tabular}

\section{Optimization of exogenous amino donor}

From the above results, we consider that ammonium chloride as an amino donor plays an important role in improving the ectoine production. Therefore, the types and concentrations of amino donors should be optimized. As shown in Figure. 3, the maximal ectoine output (10.2 g/L) was obtained by ammonium sulfate addition, higher than that obtained by ammonium chloride addition $(7.3 \mathrm{~g} / \mathrm{L})$ and sodium glutamate addition $(6.2 \mathrm{~g} / \mathrm{L})$. With the concentration of amino donor increasing, the titer presented a trend that changed from increase to decrease. And the maximum titer was obtained when the concentration of $\mathrm{NH}_{4}{ }^{+}$(for ammonium salt) $/ \mathrm{NH}_{3}{ }^{+}$(for sodium glutamate) was $152 \mathrm{mM}$, no matter it is under the condition of ammonium sulfate (Figure. 3A), ammonium chloride (Figure. 3B) or sodium glutamate addition (Figure. $3 \mathrm{C}$ ). The concentration of $\mathrm{NH}_{4}{ }^{+} / \mathrm{NH}_{3}{ }^{+}$had little effect on the growth rate of bacteria when the concentration of $\mathrm{NH}_{4}{ }^{+} / \mathrm{NH}_{3}{ }^{+}$was less than or equal to $152 \mathrm{mM}$. However, with the concentration 
of $\mathrm{NH}_{4}{ }^{+} / \mathrm{NH}_{3}{ }^{+}$reaching to $228 \mathrm{mM}$, the growth of bacteria was significantly inhibited, which was viewed as an important reason for the decrease of total glucose consumption and ectoine production. Although all these three amino donors improved ectoine biosynthesis, ammonium sulfate was the best while sodium glutamate was the worst. This might be attributed to the higher transport efficiency of ammonium sulfate compared with sodium glutamate. Overall, ammonium sulfate $(76 \mathrm{mM})$ was chosen to act as final exogenous amino donor after optimization.

\section{Effect of $\mathrm{NH}_{4}{ }^{+}$on the relevant metabolic pathways}

Results above indicated the supplement of $\mathrm{NH}_{4}{ }^{+}$was of great importance for improving ectoine production. We anticipated the participation of ammonium sulfate made a difference to the key genes in ammonium metabolic pathways and ectoine synthesis pathway. Thus, the transcription levels of relative genes were investigated under addition of $76 \mathrm{mM}$ ammonium sulfate or not (control).

Ammonium is utilized as the main nitrogen source via two stages of uptake and assimilation. After ammonium is transported into the cells, assimilation proceeds via glutamate dehydrogenase (GDH) encoded by gdhA or glutamine synthetase/glutamate synthase (GS/GOGAT) encoded by $g / n A$ and $g / t B$ separately, depending on the ammonium availability in the medium $[28,29]$. In the study, the transcription levels of $g d h A$ and gltB increased by 3.36 and 2.92 times respectively, whereas the transcription levels of $g / n A$ decreased significantly compared with those of the control (Figure. 4). The up-regulated gene gltB promoted the synthesis of glutamate in strains over the process of fermentation. The high expression of $g d h A$ could also enhance the accumulation of glutamate [30]. And the downregulated gene $g \ln A$ indicated the inhibition of glutamine synthesis but the promotion of glutamate accumulation. Furthermore, the glutamate as an essential substance could be directly involved in ectoine synthesis through transamination (Figure. 1). Therefore, the ammonium sulfate addition could act as boost in ectoine synthesis by improving glutamate synthesis.

Aspartokinase (AK), EctA, EctB as well as EctC played significant roles in the pathway of ectoine synthesis. As depicted in Figure. 4, the transcription levels of the aspartate kinase gene (lysC) was up regulated by 2.05 folds, which demonstrated that the ability of aspartate metabolism to produce downstream products was improved. Obvious increases in the transcription levels of ect $A B C$ acted as a main gene cluster in ectoine synthesis could also be seen. the transcription levels of ect $B$ was up-regulated by $6.84 \mathrm{folds}$, higher than $\operatorname{ect} A$ (3.93 folds) and ectC (1.78 folds). This result indicated that EctB was the most important enzyme among the key enzyme of the ectoine synthesis, which was consistent with the results previously reported [23]. It was speculated that the ammonium sulfate addition enhanced the supplement of the precursor $L$-aspartate- $\beta$-semialdehyde and glutamate, providing affluent co-substrate for the key enzyme EctB. At the same time, the strong expression of ectABC, especially ectB, promoted the flow of substrate to the ectoine synthesis pathway, improving the ectoine production.

\section{Fermentation performance in a 7.5L bioreactor}

To assess the overall production performance of $E$. coli ET08 under the addition of exogenous ammonium sulfate $(76 \mathrm{mM})$, ectoine fermentation in a $7.5 \mathrm{~L}$ bioreactor with feeding batch fermentation using two-stage feed was conducted. As shown in Figure. 5, the ectoine concentration reached the maximum (36.5 g/L) at $36 \mathrm{~h}$. At the first phase of fermentation ( $0 \mathrm{~h} \sim 18 \mathrm{~h}$ ), the bacteria grew fast, but just $9.4 \mathrm{~g} / \mathrm{L}$ extracellular ectoine titer could be seen. At the second phase of fermentation $(18 \mathrm{~h} \sim 36 \mathrm{~h}$ ), the ectoine titer accumulated rapidly even though there was a slow growth in dry cell weight, reaching $27 \mathrm{~g} / \mathrm{L}$ at about $30 \mathrm{~h}$ and remaining until the end of the fermentation. The specific ectoine production and productivity reached $1.4 \mathrm{~g} / \mathrm{g} \mathrm{DCW}$ and $1.01 \mathrm{~g} / \mathrm{L} / \mathrm{h}$ respectively. Plus, the yield of ectoine was 
$0.3 \mathrm{~g} / \mathrm{g}$ glucose. To our best knowledge, our work shows the highest ectoine titer and yield from glucose synthesized by $E$. coli., and still has room for further improvement. Compared with previous studies (Table 4), whole-cell catalysis seems to have certain advantages in yield, but it requires the addition of extra glycerol and aspartate, which results in high cost of extra substrate, cell culture before catalytic reaction. Although $C$. glutamicum ectABC ${ }^{\text {opt }}$ [23] achieved higher titer, the yield was only $0.19 \mathrm{~g} / \mathrm{g}$, which was lower than our yield. Thus, the metabolic engineered strain $E$. coli. ET08 and the fermentation strategy of supplementing amino donor shows a promising value for industrial production of ectoine.

Table 4

Microbial production of ectoine using different fermentative strains or biocatalysts.

\begin{tabular}{|c|c|c|c|c|c|c|}
\hline Strain & $\begin{array}{l}\text { Titer } \\
(\mathrm{g} / \mathrm{L})\end{array}$ & $\begin{array}{l}\text { Specific } \\
\text { production } \\
\text { (g/g DCW) }\end{array}$ & $\begin{array}{l}\text { Yield } \\
(g / g)\end{array}$ & $\begin{array}{l}\text { Productivity } \\
\text { (g/L/h) }\end{array}$ & Process strategy & Reference \\
\hline E. coli ET08 & 36.5 & 1.4 & 0.30 & 1.01 & Fed-batch & This work \\
\hline E. coli Ect05 & 25.1 & 0.8 & 0.11 & 0.84 & Fed-batch & {$[22]$} \\
\hline $\begin{array}{l}\text { E. coli BW25113 (pBAD- } \\
\text { ectABC) }\end{array}$ & 25.1 & 4.1 & - & $1.04^{c}$ & $\begin{array}{l}\text { Whole-cell } \\
\text { catalysis }^{a}\end{array}$ & [21] \\
\hline E. coli ECT2 & 12.7 & - & 1.27 & $0.53^{c}$ & $\begin{array}{l}\text { Whole-cell } \\
\text { catalysis }^{a}\end{array}$ & [34] \\
\hline C. glutamicum ectABCopt & 65.3 & - & 0.19 & 1.16 & Fed-batch & {$[23]$} \\
\hline $\begin{array}{l}\text { Chromohalobacter } \\
\text { salexigens DSM3043 }\end{array}$ & 32.9 & 0.5 & - & 1.35 & $\begin{array}{l}\text { continuous } \\
\text { reactors with cell } \\
b\end{array}$ & [19] \\
\hline \multicolumn{7}{|c|}{${ }^{a}$ Whole-cell catalysis using aspartate and glycerol as substrates at a high cell density. } \\
\hline \multicolumn{7}{|c|}{${ }^{b}$ A special fermentation process using two continuously operated bioreactors. } \\
\hline
\end{tabular}

\section{Conclusions}

In this study, we constructed an efficient strain E. coli ET08 by metabolic engineering. By optimizing amino donor and analyzing the transcription levels, we could conclude that ammonium sulfate, as the optimal amino donor, has a positive effect on ectoine synthesis. Batch fermentation of the E. coli ET08 with supplementing ammonium sulfate led to an accumulation of $36.5 \mathrm{~g} / \mathrm{L}$ ectoine, and the specific ectoine production, yield and productivity reached $1.4 \mathrm{~g} / \mathrm{g} \mathrm{DCW}, 0.3 \mathrm{~g} / \mathrm{g}$ glucose and $1.01 \mathrm{~g} / \mathrm{L} / \mathrm{h}$ respectively. To the best of our knowledge, this is the first report about the effect of exogenous amino donor on ectoine fermentation by metabolic engineered strain. It provides a novel strategy for the synthesis of ectoine by engineered strain in industry. This research provides the basis for an effective process for ectoine production and could also be used to produce other high value amino acid derivative.

\section{Methods}




\section{Strains, plasmids and culture medium}

The strains and plasmids constructed and used in this study are listed in Table 1. All restriction digest enzymes, DNA polymerase and DNA ligase were obtained from Takara Bio Inc. (Dalian, China). Oligonucleotides were synthesized by GENEWIZ Bio Inc. (Suzhou, China). Ectoine was purchased from Sigma-Aldrich (Shanghai, China). The seed culture medium was the Luria-Bertani (LB) medium. The fermentation culture medium in shake flasks contained (per liter) $5 \mathrm{~g}$ glucose, $20 \mathrm{~g}$ yeast extract, $5 \mathrm{~g}$ glycerol, $0.5 \mathrm{~g} \mathrm{NaCl}, 2.5 \mathrm{~g} \mathrm{KH}_{2} \mathrm{PO}_{4}, 7.5 \mathrm{~g} \mathrm{~K}_{2} \mathrm{HPO}_{4}, 1 \mathrm{~g}$ MgSO4.7 $\mathrm{H}_{2} \mathrm{O}, 15 \mathrm{~g}$ magnesium carbonate hydroxide pentahydrate. The fed-batch fermentation culture medium in a $7.5 \mathrm{~L}$ bioreactor contained (per liter) $15 \mathrm{~g}$ glucose, $20 \mathrm{~g}$ yeast extract, $5 \mathrm{~g}$ glycerol, $0.5 \mathrm{~g} \mathrm{NaCl}, 2.5 \mathrm{~g} \mathrm{KH}_{2} \mathrm{PO}_{4}, 7.5 \mathrm{~g}$ $\mathrm{K}_{2} \mathrm{HPO}_{4}, 1 \mathrm{~g} \mathrm{MgSO} 4 \cdot 7 \mathrm{H}_{2} \mathrm{O}, 10 \mathrm{~g}$ ammonium sulfate.

\section{Construction of plasmids and gene knockout}

The ECTABC gene (ectABC) was amplified from the genome of Halomonas venusta using the primers ET01-F and ET01-R. The PCR products were purified and then ligated into the linearized vector pTrc99a by in-fusion cloning with restriction sites of $K p n I$ and $B a m H I$, forming plasmid pTrc-ectABC. For the construction of the plasmid pET-ectABC, the ect $A B C$ was amplified by PCR with ET02-F and ET02-R using the genomic DNA of $H$. venusta as a template. The PCR products were purified and then inserted into pET-28a by in-fusion cloning with restriction sites of $B a m H I$ and Xhol. Deletion of the IysA, thrA, pykF, IdhA and pta genes were carried out using the Red recombination method [31]. The primers used for gene cloning and chromosomal manipulation are listed in Additional file 1: Table S1.

\section{Culture conditions in shake flasks}

Seed cultures were prepared by transferring an appropriate amount of agar slant cultured cells into a $500 \mathrm{~mL}$ Erlenmeyer flask containing $50 \mathrm{~mL}$ medium and culturing at $37^{\circ} \mathrm{C}$ with shaking at $200 \mathrm{rpm}$ for $8 \mathrm{~h}$. The ectoine production of engineered strains was investigated by fed-batch culture, with a $10 \%$ inoculum size in a $500 \mathrm{~mL}$ baffled shake flask containing $50 \mathrm{~mL}$ medium, at $37^{\circ} \mathrm{C}$ with shaking at $200 \mathrm{rpm}$ for $48 \mathrm{~h}$. Both media were supplemented with $100 \mathrm{mg} / \mathrm{L}$ ampicillin. As the inducer, $0.1 \mathrm{mmol} / \mathrm{L}$ IPTG was added four hours after the fermentation began. $50 \%$ glucose was supplied at a final concentration of $20 \mathrm{~g} / \mathrm{L}$ every $12 \mathrm{~h}$.

Nitrogen sources were optimized by mixing various concentrations of yeast extract $(10 \mathrm{~g} / \mathrm{L}, 15 \mathrm{~g} / \mathrm{L}, 20 \mathrm{~g} / \mathrm{L})$ up with ammonium chloride (152 $\mathrm{mM}$ ) and sodium nitrate $(152 \mathrm{mM})$ respectively. And the medium without inorganic nitrogen addition was used as control check (CK). To optimize the exogenous amino donor, the effects of various concentrations of ammonium chloride $(0,38,76,152,228 \mathrm{mM})$, ammonium sulfate $(0,19,38,76114 \mathrm{mM})$ and sodium glutamate $(0,38,76,152,228 \mathrm{mM})$ were investigated in shake-flask tests.

\section{Two-stage fed-batch fermentation in a $7.5 \mathrm{~L}$ bioreactor}

Primary seed cultures were prepared by transferring an appropriate amount of agar slant cultured cells into a $30 \mathrm{~mL}$ Screw glass sample bottle containing $5 \mathrm{~mL}$ medium and culturing at $37^{\circ} \mathrm{C}$ with orbital shaking at $200 \mathrm{rpm}$ for about $10 \mathrm{~h}$. The bacterial solution was inoculated into a $1 \mathrm{~L}$ shake flask containing $200 \mathrm{~mL}$ of seed medium, inoculated in an amount of $1 \%$, and cultured at $37^{\circ} \mathrm{C}$ for $10 \mathrm{~h}$ at $200 \mathrm{rpm}$ to prepare a secondary seed culture. The ectoine production of engineered strains was investigated by fed-batch culture, with a $15 \%(\mathrm{v} / \mathrm{v})$ inoculum size in a $7.5 \mathrm{~L}$ bioreactor (New Brunswick BioFlo/CelliGen 115, New Brunswick, Germany) containing $3.5 \mathrm{~L}$ medium. The pH was automatically controlled at 7.0 by adding $\mathrm{NH}_{4} \mathrm{OH}(25 \%, \mathrm{v} / \mathrm{v})$, and the temperature was maintained at $37^{\circ} \mathrm{C}$. The aeration rate and agitation speed were $1.5 \mathrm{vvm}$ and $600 \mathrm{rpm}$, respectively. The glucose concentration constantly 
fluctuated during $0 \mathrm{~h} \sim 24 \mathrm{~h}$, and then it reached almost zero after $24 \mathrm{~h}$. As the inducer, $0.1 \mathrm{mmol} / \mathrm{L}$ IPTG was added when the optical density at $600 \mathrm{~nm}\left(\mathrm{OD}_{600}\right)$ reached 0.4 .

\section{RNA sample preparation and RTqPCR analysis}

As the fed-batch fermentation reached $36 \mathrm{~h}$, the maximum production was reached. At this timepoint, the transcriptional levels of the key genes in ammonium metabolic pathways and ectoine synthesis were determined. Total RNA was isolated using RNAiso Plus (9108Q, TaKaRa Biotechnology Company, China). The synthesis of cDNA was then performed with PrimeScriptTM II 1st Strand cDNA Synthesis Kit (6210A, TaKaRa Biotechnology Company, China), using the total RNA as template. Real-time PCR (StepOnePlusTM Real-Time PCR System, Applied Biosystems, USA) was carried out with SYBR® Premix Ex TaqTM (RR420Q, TaKaRa Biotechnology Company, China) as fluorochrome, with $16 \mathrm{~S}$ rDNA as an endogenous control gene. The primers used for qPCR were designed according to the $E$. coligenome sequence and were summarized in Additional file 1: Table S2. The amplification program consisted of one cycle at $95^{\circ} \mathrm{C}$ for $30 \mathrm{~s}$, followed by 40 cycles at $95^{\circ} \mathrm{C}$ for $5 \mathrm{~s}, 60^{\circ} \mathrm{C}$ for $30 \mathrm{~s}$. All reactions were repeated three folds. Data from RT-qPCR were treated with the $2^{-\Delta \Delta C t}$ method for relative quantification [32]. To present the results in a better way, the formula $2^{-\Delta \Delta C t}$ was multiplied by 1 . Therefore, the comparative expression level of each gene under the control was always 1 [33].

\section{Analytic methods}

Cell growth was monitored by measuring the absorbance at $600 \mathrm{~nm}\left(\mathrm{OD}_{600}\right)$ that was then converted to dry cell weight (DCW) by a calibration curve. The concentration of extracellular ectoine was determined via highperformance liquid chromatography (HPLC) using TSKgel ODS-80Ts column (4.6 × $250 \mathrm{~mm}$, Tosoh, Tokyo) with an acetonitrile/water mixture $(2: 98 \mathrm{v} / \mathrm{v})$ at a flow rate of $0.5 \mathrm{~mL} / \mathrm{min}$ as the mobile phase. Ectoine was monitored by a UV detector at a wavelength of $210 \mathrm{~nm}$. The residual sugar in the fermentation broth was measured using an SBA$40 \mathrm{C}$ biological analyzer (Shandong Academy of Sciences, China).

\section{Declarations}

\section{Ethics approval and consent to participate}

Not applicable

\section{Consent for publication}

Not applicable

\section{Availability of data and materials}

All data generated or analyzed during this study are included in this published article (and its Additional file 1).

\section{Competing interests}

The authors declare that they have no competing interests

\section{Funding}

This work was supported by the National Key R\&D Program of China (No. 2019YFA0905200), the National Natural Science Foundation of China (No. 21776133), the Jiangsu Synergetic Innovation Center for Advanced Bio- 
Manufacture (No. XTB1804).

Authors' contributions

ZH performed the experiments and drafted the manuscript. LS, ZH and LZS designed this study. CYY, DYS, ZM and MYQ supervised the experiments and helped to draft the manuscript. LS and XH conceived the study and reviewed the final manuscript. All authors read and approved the final manuscript.

Acknowledgements

Not applicable

\section{References}

1. Galinski EA, Pfeiffer HP, Trüper HG: Tetrahydro-2- methyl-4-pyrimidinecarboxylic acid. a novel cyclic amino acid from halophilic phototrophic bacteria of the genus Ectothiorhodospira. Eur J Biochem 1985, 149:135-139.

2. Kunte HJ, Lentzen G, Galinski EA: Industrial production of the cell protectant ectoine: protection mechanisms, processes, and products. Curr Biotechnol 2014, 3:10-25.

3. Roychoudhury A, Haussinger D, Oesterhelt F: Effect of the compatible solute ectoine on the stability of the membrane proteins. Protein Pept Lett 2012, 19:791-794.

4. Boroujeni MB, Nayeri H: Stabilization of bovine lactoperoxidase in the presence of ectoine. Food Chem 2018, 265:208-215.

5. Nakayama H, Yoshida K, Ono H, Murooka Y, Shinmyo A: Ectoine, the compatible solute of Halomonas elongata, confers hyperosmotic tolerance in cultured tobacco cells. Plant Physiol 2000, 122:1239-1247.

6. Graf R, Anzali S, Buenger J, Pfluecker F, Driller H: The multifunctional role of ectoine as a natural cell protectant. Clin Dermatol 2008, 26:0-333.

7. Kentaro F, Toshihiro Y, Shoji S: Ectoine alters subcellular localization of inclusions and reduces apoptotic cell death induced by the truncated Machado-Joseph disease gene product with an expanded polyglutamine stretch. Neurobiol Dis 2005, 20:170-178.

8. Unfried K, Kramer U, Sydlik U, Autengruber A, Bilstein A, Stolz S, Marini A, Schikowski T, Keymel S, Krutmann J: Reduction of neutrophilic lung inflammation by inhalation of the compatible solute ectoine: a randomized trial with elderly individuals. Int J Chronic Obstruct Pulm Dis 2016, 11:2573-2583.

9. Calderon MI, Vargas C, Rojo F, Iglesias-Guerra F, Csonka LN, Ventosa A, Nieto JJ: Complex regulation of the synthesis of the compatible solute ectoine in the halophilic bacterium Chromohalobacter salexigens DSM 3043T. Microbiology 2004, 150:3051-3063.

10. Göller K, Ofer A, Galinski EA: Construction and characterization of an NaCl-sensitive mutant of Halomonas elongata impaired in ectoine biosynthesis. FEMS Microbiol Lett 1998:293-300.

11. Schwibbert K. MSA, Bagyan I., Heidrich G., Lentzen G., Seitz H., et al: A blueprint of ectoine metabolism from the genome of the industrial producer Halomonas elongata DSM 2581T. Environ Microbiol 2011, 13:1973-1994.

12. Li YJ, Wei HB, Wang T, Xu QY, Zhang CL, Fan XG, Ma Q, Chen N, Xie XX: Current status on metabolic engineering for the production of I-aspartate family amino acids and derivatives. Bioresour Technol 2017, 245:1588-1602.

13. Bursy J, Kuhlmann AU, Pittelkow M, Hartmann H, Jebbar M, Pierik AJ, Bremer E: Synthesis and uptake of the compatible solutes ectoine and 5-hydroxyectoine by Streptomyces coelicolor A3(2) in response to salt and heat stresses. Appl Environ Microbiol 2008, 74:7286-7296. 
14. Louis P, Galinski EA: Characterization of genes for the biosynthesis of the compatible solute ectoine from Marinococcus halophilus and osmoregulated expression in Escherichia coli. Microbiology 1997, 143 (Pt 4):1141-1149.

15. Zhao B, Lu W, Yang L, Zhang B, Wang L, Yang SS: Cloning and characterization of the genes for biosynthesis of the compatible solute ectoine in the moderately halophilic bacterium Halobacillus dabanensis D-8T. Curr Microbiol 2006, 53:183-188.

16. Reshetnikov AS, Khmelenina VN, Trotsenko YA: Characterization of the ectoine biosynthesis genes of haloalkalotolerant obligate methanotroph “Methylomicrobium alcaliphilum 20Z”. Arch Microbiol 2006, 184:286297.

17. Zhang B, Bao X, Wang L, Yang SS: Cloning and characterization of the gene cluster for biosynthesis of ectoine from Nesterenkonia halobia DSM 20541. Journal of Microbiology 2008, 46:309-318.

18. Sauer T, Galinski EA: Bacterial milking: a novel bioprocess for production of compatible solutes. Biotechnol Bioeng 1998, 57:306-313.

19. Fallet C, Rohe P, Franco-Lara E: Process optimization of the integrated synthesis and secretion of ectoine and hydroxyectoine under hyper/hypo-osmotic stress. Biotechnol Bioeng 2010, 107:124-133.

20. Becker J, Schäfer R, Kohlstedt M, Harder BJ, Borchert NS, Stöveken N, Bremer E, Wittmann C: Systems metabolic engineering of Corynebacterium glutamicum for production of the chemical chaperone ectoine. Microb Cell Fact 2013, 12:110.

21. He YZ, Gong J, Yu HY, Tao Y, Zhang S, Dong ZY: High production of ectoine from aspartate and glycerol by use of whole-cell biocatalysis in recombinant Escherichia coli. Microb Cell Fact 2015, 14:55.

22. Ning YK, Wu XJ, Zhang CL, Xu QY, Chen N, Xie XX: Pathway construction and metabolic engineering for fermentative production of ectoine in Escherichia coli. Metab Eng 2016, 36:10-18.

23. Gießelmann G, Dietrich D, Jungmann L, Kohlstedt M, Wittmann C: Metabolic engineering of Corynebacterium glutamicum for high-level ectoine production: design, combinatorial assembly, and implementation of a transcriptionally balanced heterologous ectoine pathway. Biotechnol J 2019, 14.

24. Xu DL, Yao HQ, Cao CH, Xu ZX, Li S, Xu Z, Zhou JH, Feng XH, Xu H: Enhancement of epsilon-poly-L-lysine production by overexpressing the ammonium transporter gene in Streptomyces albulus PD-1. Bioprocess Biosyst Eng 2018, 41:1337-1345.

25. Yue GJ, Yu JL, Zhang X, Tan TW: The influence of nitrogen sources on ethanol production by yeast from concentrated sweet sorghum juice. Biomass Bioenergy 2012, 39:48-52.

26. Aharonowitz Y, Demain AL: Nitrogen nutrition and regulation of cephalosporin production in Streptomyces clavuligerus. Can J Microbiol 1979, 25:61-67.

27. Hawkesford M, Horst W, Kichey T, Lambers H, Schjoerring J, Skrumsager MI, White P: Nutritional physiology: functions of macronutrient. In Marschner P. Edited by Plants MsMNoH. San Diego, USA: Elsevier Ltd; 2012: 135189. [Mineral nutrition of higher plants].

28. Reitzer L: Nitrogen assimilation and global regulation in Escherichia coli. Annu Rev Microbio/ 2003, 57:155.

29. Merrick MJ, Edwards RA: Nitrogen control in bacteria. Microbiol Rev 1995, 59:604-622.

30. Huang BQ, Qin PY, Xu ZW, Zhu RY, Meng YH: Effects of CaCl2 on viscosity of culture broth, and on activities of enzymes around the 2-oxoglutarate branch, in Bacillus subtilis CGMCC 2108 producing poly-( $\mathrm{Y}$-glutamic acid). Bioresour Technol 2011, 102:3595-3598. 
31. Datsenko KA, Wanner BL: One-step inactivation of chromosomal genes in Escherichia coli K-12 using PCR products. Proc Natl Acad Sci USA 2000, 97:6640-6645.

32. Livak KJ, Schmittgen TD: Analysis of relative gene expression data using real-time quantitative PCR and the 2$\Delta \Delta$ Ct Method. Methods 2000, 25:402-408.

33. Liu XL, Zhu P, Jiang RF, Wu LT, Feng XH, Li S, Xu H: Enhancement of welan gum production in Sphingomonas sp. HT-1 via heterologous expression of Vitreoscilla hemoglobin gene. Carbohydr Polym 2017, 156:135-142.

34. Chen J, Liu P, Chu X, Chen J, Zhang H, Rowley DC, Wang H: Metabolic Pathway Construction and Optimization of Escherichia coli for High-Level Ectoine Production. Curr Microbiol 2020.

\section{Figures}

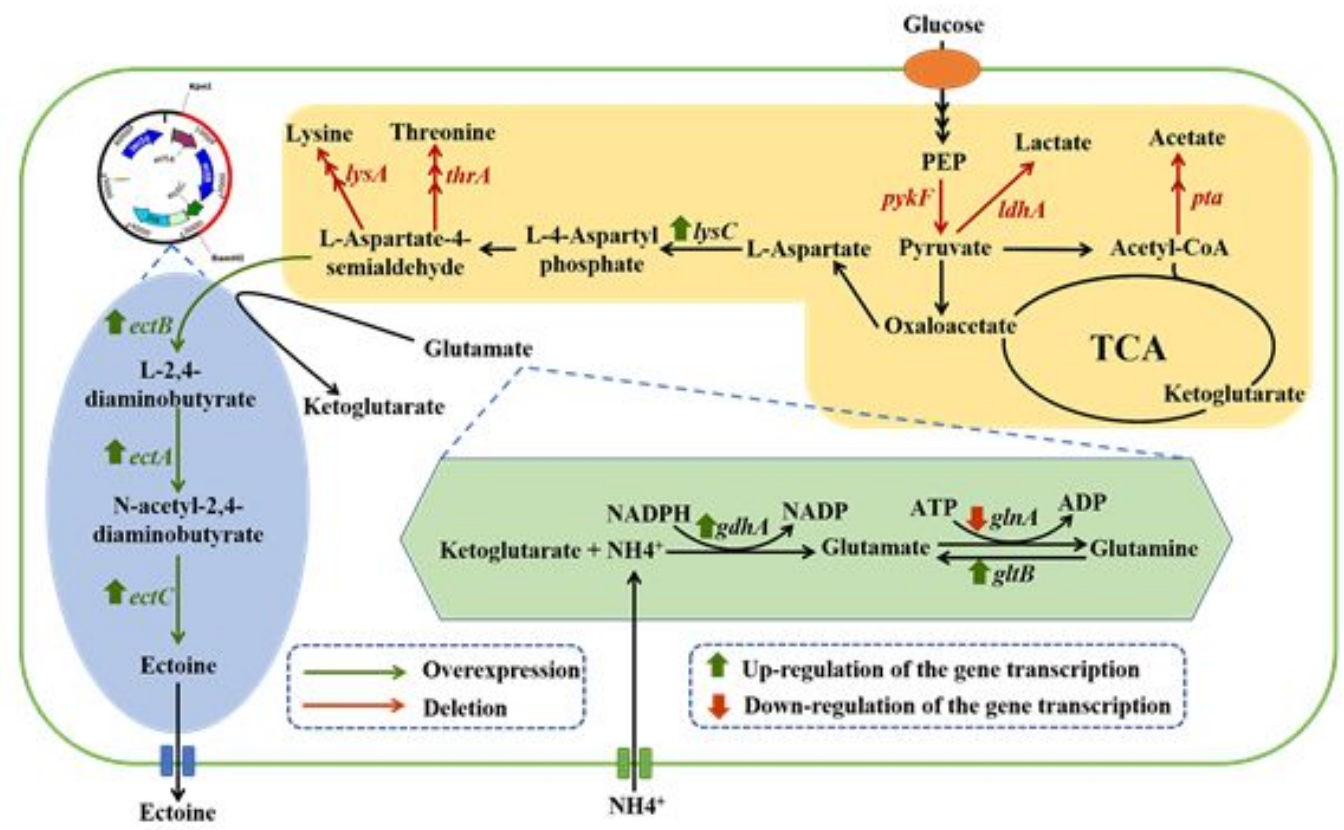

Figure 1

Related metabolic pathways for the synthesis of ectoine in engineered E. coli. The genes marked in green indicate the key genes of biosynthetic ectoine introduced into the engineered E. coli. The genes marked in red indicate deletion of the corresponding gene. Abbreviations: PEP, phosphoenolpyruvate. 


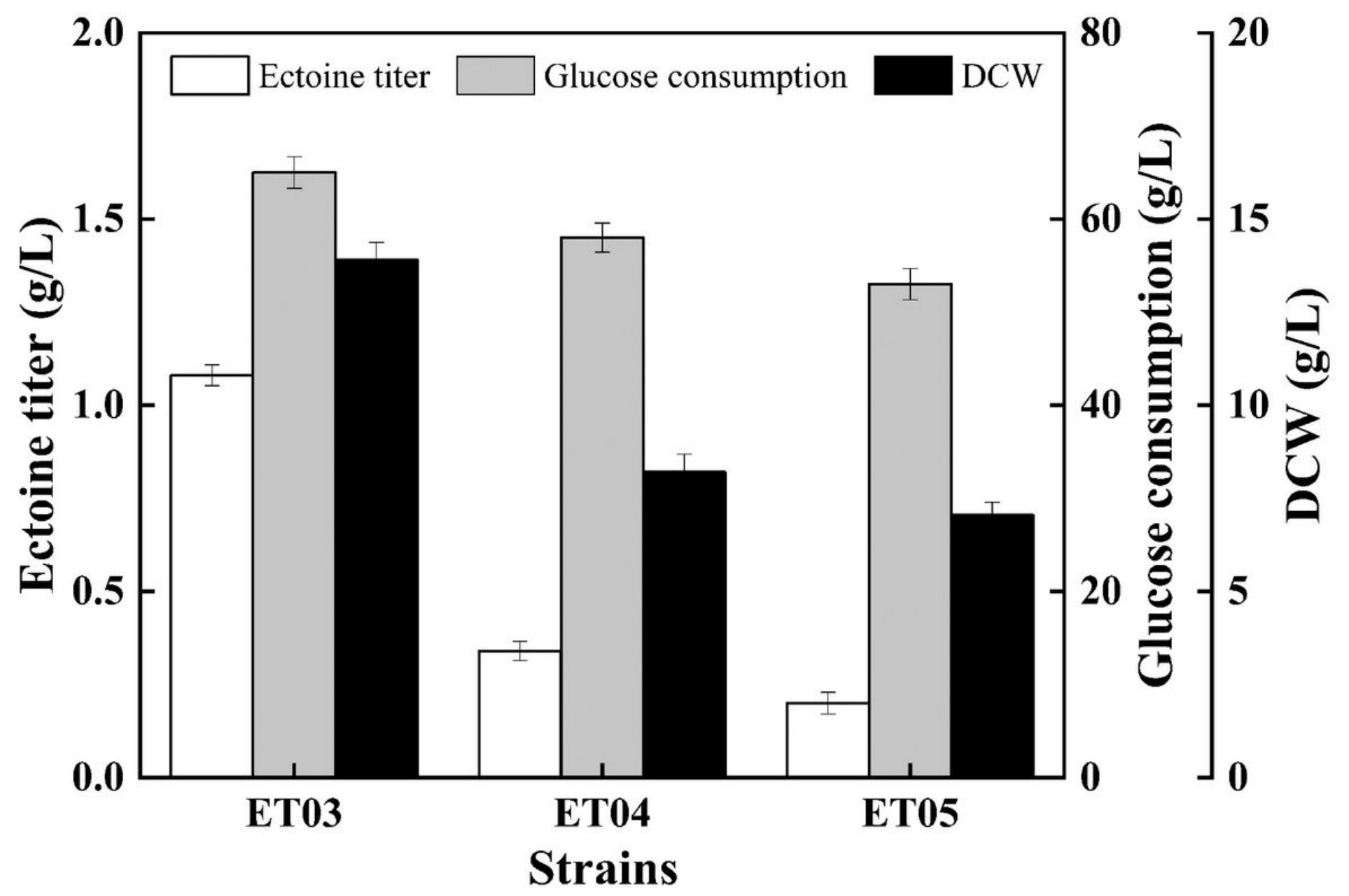

Figure 2

The effects of lysA and thrA deletion on ectoine fermentation. 

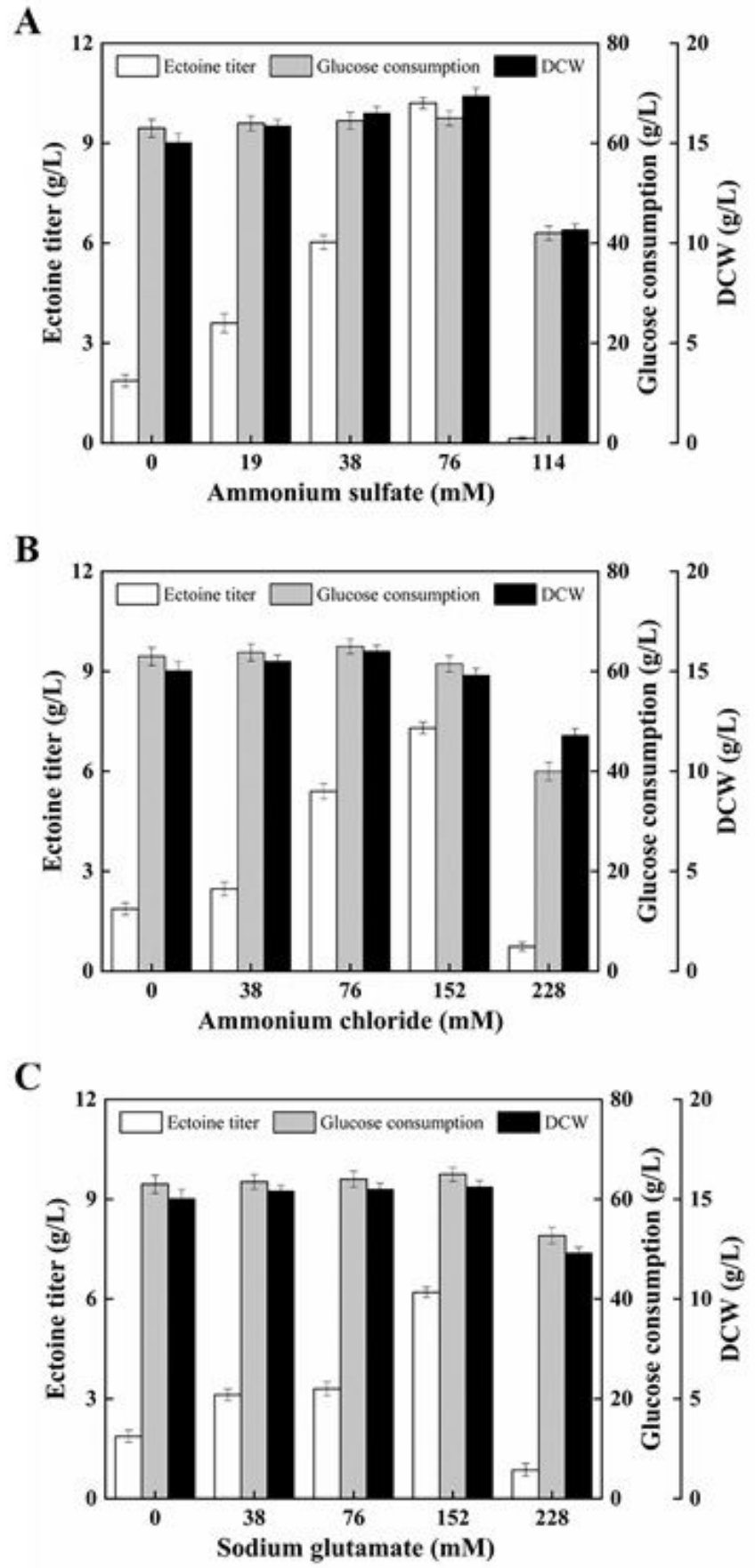

Figure 3

Effect of different amino donors on ectoine fermentation. A: Ectoine titer, DCW and glucose consumption of ET08 with ammonium sulfate $(0,19,38,76$ and $114 \mathrm{mM})$ addition; $B$ : Ectoine titer, DCW and glucose consumption of ET08 with ammonium chloride $(0,38,76,152,228 \mathrm{mM})$ addition; C: Ectoine titer, DCW and glucose consumption of ET08 with sodium glutamate $(0,38,76,152,228 \mathrm{mM})$ addition. 


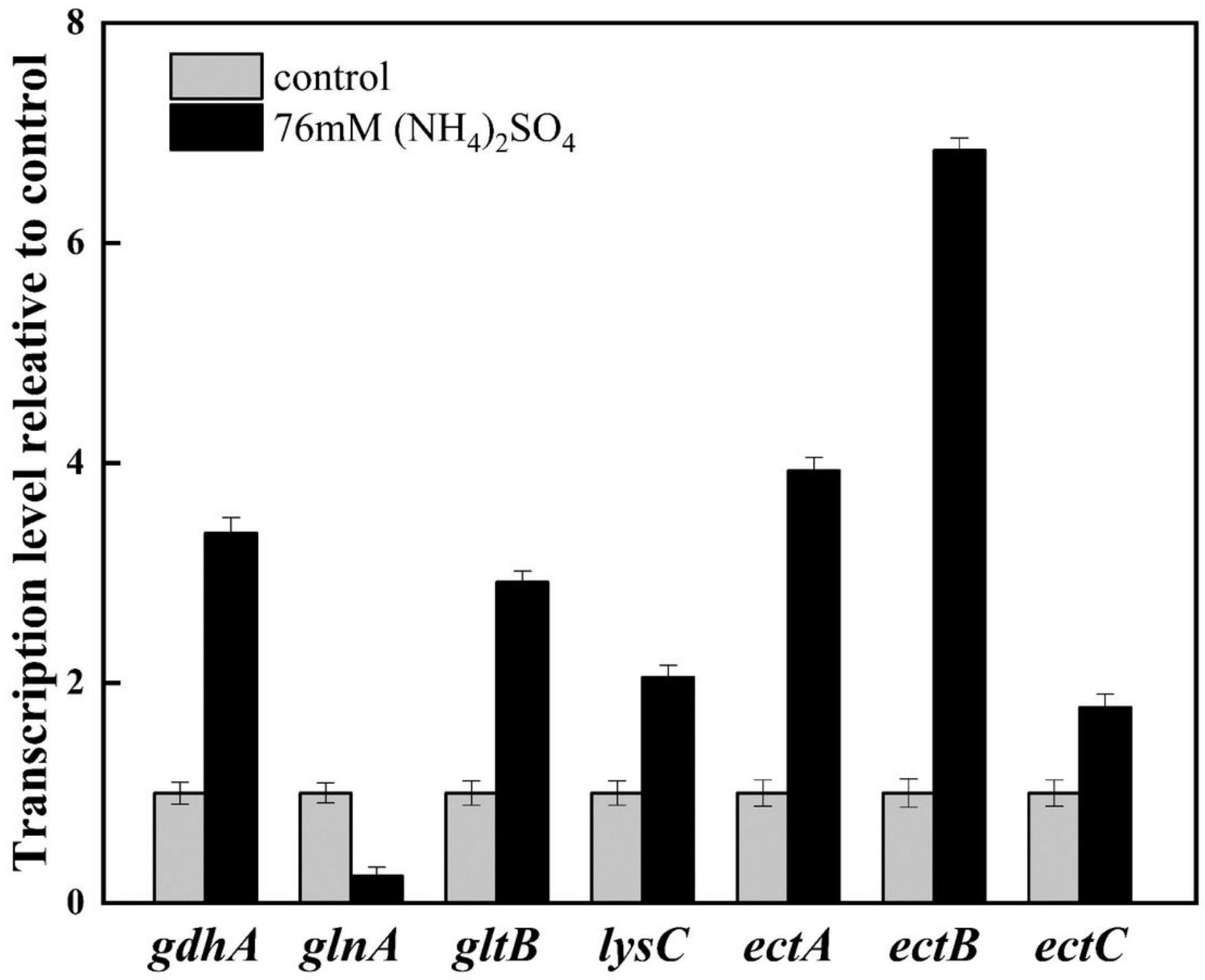

Figure 4

Transcription levels of the key genes in ammonium metabolic pathways and ectoine synthesis. The level of transcription was calculated relative to transcription of the control ( $0 \mathrm{mM}$ ammonium sulfate), which were defined as 1. The error bars indicate the standard deviation of three samples taken from the same RNA sample. 


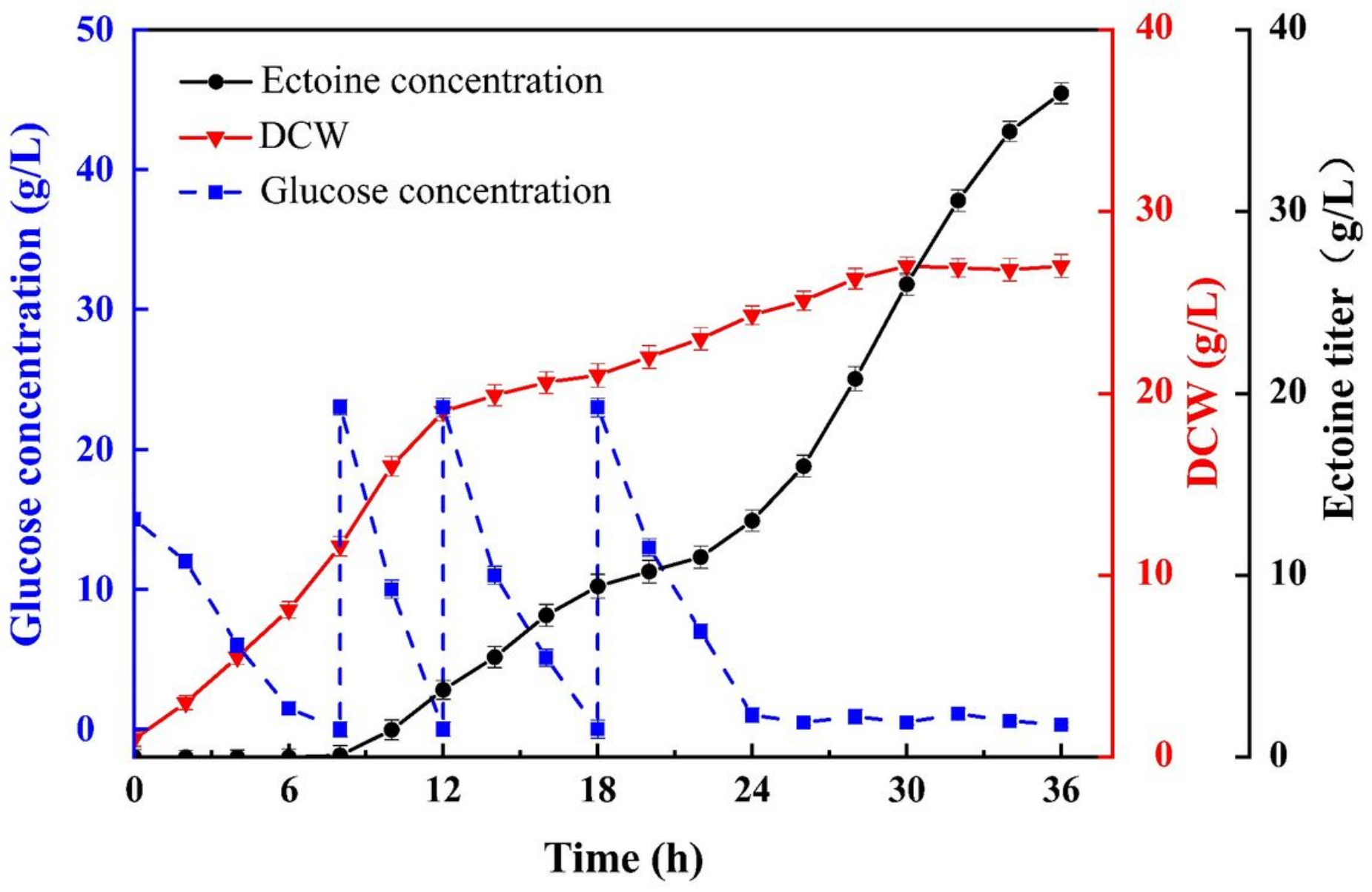

Figure 5

Fed-batch fermentation of ET08 in a $7.5 \mathrm{~L}$ bioreactor with the supplement of ammonium sulfate.

\section{Supplementary Files}

This is a list of supplementary files associated with this preprint. Click to download.

- Additionalfile1.docx 